\title{
Endoscopic removal of an eroded magnetic sphincter augmentation device
}

Magnetic sphincter augmentation with the LINX device (Torax Medical, Shoreview, Minnesota, USA) is an effective treatment for gastroesophageal reflux disease (GERD). It is associated with shorter operating time and lower rate of gas bloat [1]. Erosion is estimated to range from $0.1 \%$ to $1.2 \%$; it may be higher with the smaller device. The most common method for device removal involves a combined endoscopic-laparoscopic approach [2,3]. Endoscopic removal using a bipolar grasping device has also been reported [4]. We report the first case of LINX erosion in the United Kingdom and its endoscopic removal using Olympus loop cutters.

A 57-year-old woman with GERD underwent LINX implantation in April 2013 ( Fig.1). She did not have a hiatus hernia and manometry was normal. Good reflux control was achieved. In February 2017, the patient experienced acute intermittent dysphagia and chest pain. Endoscopy showed device erosion. Under general anesthesia, the LINX device was divided at two points using a loop cutter (Olympus Medical Systems Corp., Tokyo, Japan), and was extracted endoscopically using a grasper with the application of rotational traction. The mucosal defects in the esophagus were closed with two Olympus QuickClips ( $\triangleright$ Video 1 ). The patient was discharged with proton pump inhibitors on postoperative Day 1 after a normal oral contrast swallow study (॰ Fig.2).

Endoscopy_UCTN_Code_CPL_1AH_2AH

Competing interests

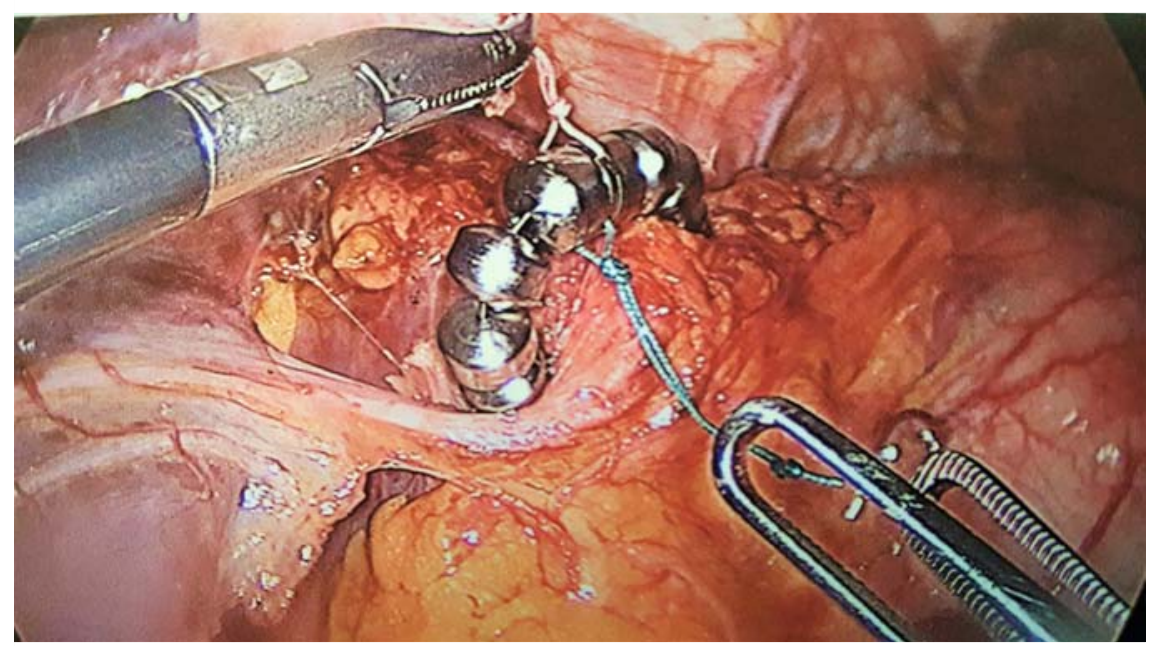

Fig. 1 Laparoscopic implantation of LINX device (Torax Medical, Shoreview, Minnesota, USA). A size 12 bead device was implanted.

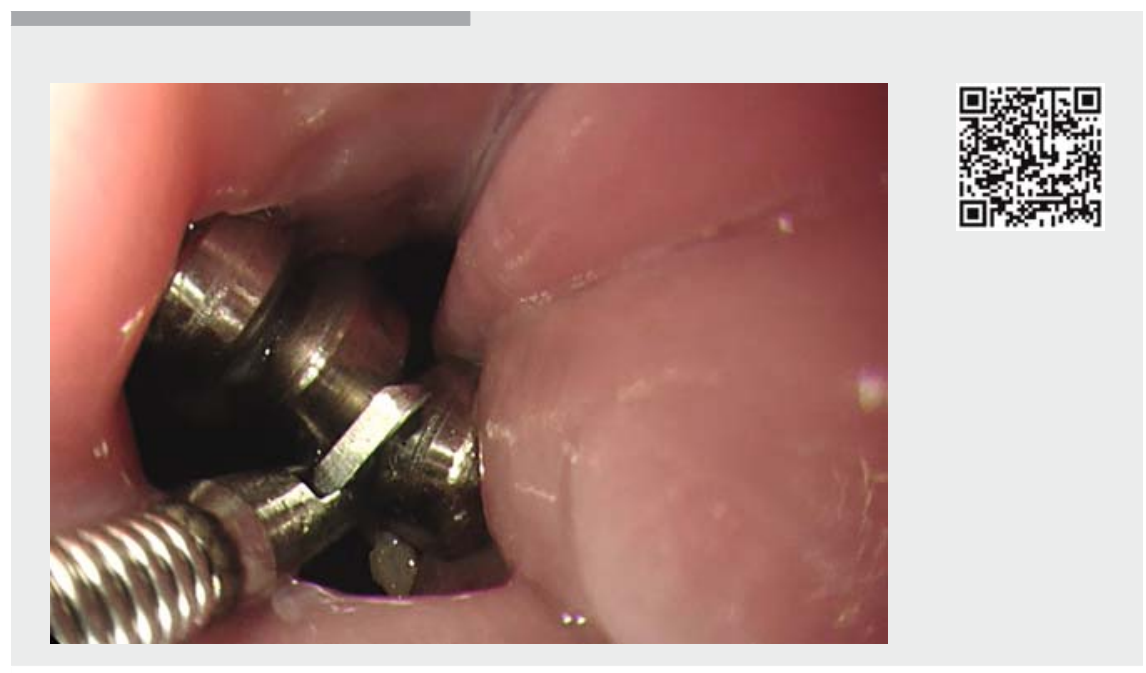

$\checkmark$ Video 1 Seven steps for removal of an eroded magnetic sphincter augmentation device (LINX; Torax Medical, Shoreview, Minnesota, USA) from the esophagus. 1) Identification of LINX erosion. 2) Endocut of visible LINX wire. 3) Initial retrieval with forceps. 4) Endocut of anchor bead. 5) Final extraction of LINX device. 6) Basket retrieval. 7) Mucosal defect closure with endoclips. 


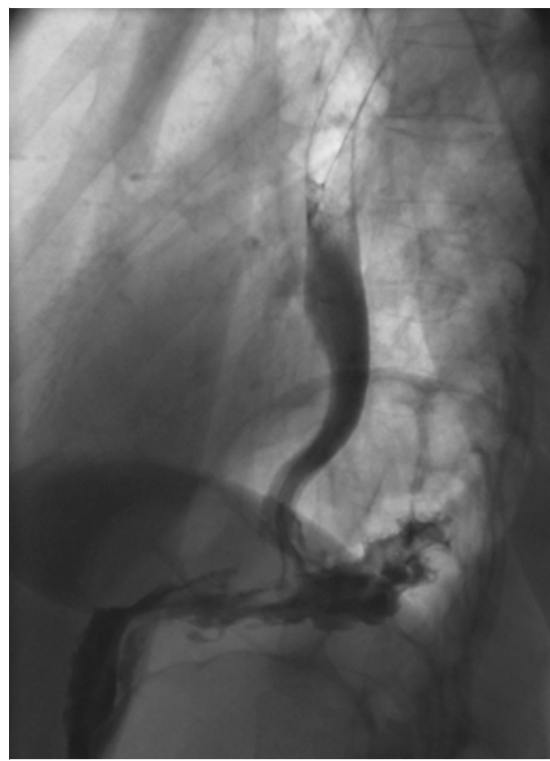

- Fig. 2 Contrast swallow study confirmed esophageal integrity after removal of the LINX device (Torax Medical, Shoreview, Minnesota, USA).
The Authors

Baldwin Po Man Yeung, Grant Fullarton

Department of Surgery, Glasgow Royal

Infirmary, Glasgow, United Kingdom

Corresponding author

Baldwin Po Man Yeung, BSc (Hons), MBChB (Hons), PhD, FRCS

Department of Surgery, Glasgow Royal Infirmary, 84 Castle Street, Glasgow G4 0SF, United Kingdom

Fax: +44-757-0693699

byeung@doctors.net.uk

\section{References}

[1] Zhang H, Dong D, Liu Z et al. Revaluation of the efficacy of magnetic sphincter augmentation for treating gastroesophageal reflux disease. Surg Endosc 2016; 30: 3684-3690

[2] Lipham JC, Taiganides PA, Louie BE et al. Safety analysis of first 1000 patients treated with magnetic sphincter augmentation for gastroesophageal reflux disease. Dis Esophagus 2015; 28: $305-311$

[3] Asti E, Siboni S, Lazzari $V$ et al. Removal of the magnetic sphincter augmentation device: surgical technique and results of a single-center cohort study. Ann Surg 2017; 265: 941 - 945

[4] Bauer M, Meining A, Kranzfelder M et al. Endoluminal perforation of a magnetic antireflux device. Surg Endosc 2015; 29: 3806 3810

\section{Bibliography}

DOI https://doi.org/10.1055/s-0043-109236

Endoscopy 2017; 49: 718-719

(c) Georg Thieme Verlag KG

Stuttgart · New York

ISSN 0013-726X

\section{ENDOSCOPY E-VIDEOS}

https://eref.thieme.de/e-videos

口及i: Endoscopy E-Videos is a free Fection, reporting 口虽 techniques in gastroenterological endoscopy. All papers include a high quality video and all contributions are freely accessible online.

This section has its own submission website at https://mc.manuscriptcentral.com/e-videos 